Tema: Aciaria Elétrica

\title{
EARLIEST LEAK DETECTION (ELD), UM NOVO CONCEITO DE SEGURANÇA NA DETECÇÃO DE VAZAMENTOS DE ÁGUA EM FORNOS ELÉTRICOS A ARCO*
}

\author{
Thiago Pinto Wandekoken ${ }^{1}$ \\ Breno Totti Maia ${ }^{2}$ \\ Paulo Hopperdizel ${ }^{3}$
}

\begin{abstract}
Resumo
Vazamentos de água em painéis refrigerados apresentam grandes riscos operacionais e de segurança nos processos de fabricação do aço, principalmente nos Fornos Elétricos a Arco. A detecção precoce de vazamentos de água pode minimizar e/ou até eliminar grandes riscos operacionais, de segurança e patrimônio. A Tecnologia ELD, desenvolvida pela Lumar Metals, traz uma proposta inovadora de monitoramento dos painéis do FEA, que através da combinação e análise de dados coletados individualmente nos painéis refrigerados é capaz de detectar vazamentos de $0,2 \mathrm{l} / \mathrm{min}$ em até 10 segundos após sua ocorrência. A coleta de dados é realizada de forma contínua nos painéis refrigerados e transmitida via wireless. Testes em escala laboratorial foram realizados, onde os vazamentos de água foram simulados através da abertura de válvulas solenoides. Nos testes em escala industrial o sistema pôde ser avaliado em suas condições reais de operação, ficando exposto ao calor, poeira, ruídos e campos eletromagnéticos. Em todas as etapas de testes realizadas a Tecnologia ELD foi capaz de detectar os menores vazamentos de água, credenciando a tecnologia para inserção no mercado.
\end{abstract}

Palavras-chave: Tecnologia ELD; Vazamentos de água em FEA; Segurança.

\section{EARLIEST LEAK DETECTION (ELD), A NEW CONCEPT OF SECURITY IN WATER LEAK DETECTION IN ELECTRIC ARC FURNACE}

\begin{abstract}
Water leakage in EAF from water cooled panels is considered to be of high operational and safety risk in the steel manufacturing process, and the early detection of the leak is an essential and necessary factor to minimize and/or eliminate such risks. ELD Technology developed by Lumar Metals brings an innovate solution that, by combining and analyzing data, detects and indicates initial leaks from $0.2 \mathrm{l} / \mathrm{min}$ up to 10 seconds after its occurrence. Laboratory and industrial scale tests were carried out successfully, accrediting the technology to market.
\end{abstract}

Keywords: ELD technology; Water leak in EAF; Safety.

1 Engenheiro de Controle e Automação, Mestrando do Programa de Pós-Graduação em Engenharia Metalúrgica e de Materiais, Instituto Federal do Espírito Santo - IFES, Engenheiro de Aplicações, Lumar Metals, sócio da ABM, Vitória, ES, Brasil.

2 Engenheiro de Metalúrgico, Diretor, Lumar Metals, sócio da ABM, Belo Horizonte, MG, Brasil.

3 Engenheiro Metalúrgico, Diretor, Lumar Metals, sócio da ABM, Porto Alegre, RS, Brasil.

* Contribuição técnica ao $45^{\circ}$ Seminário de Aciaria - Internacional, 25 a 28 de maio de 2014, Porto Alegre, RS, Brasil. 


\section{INTRODUÇÃO}

Patenteado no ano de 1899, na França, o Forno Elétrico a Arco (FEA) rapidamente tornou-se um equipamento utilizado em larga escala para a fabricação de aços. Em sua concepção construtiva original o FEA possuía revestimento refratário em sua carcaça inferior (cuba), em sua carcaça superior, na abóbada e no miolo da abóbada [1], como pode ser observado na Figura 1.
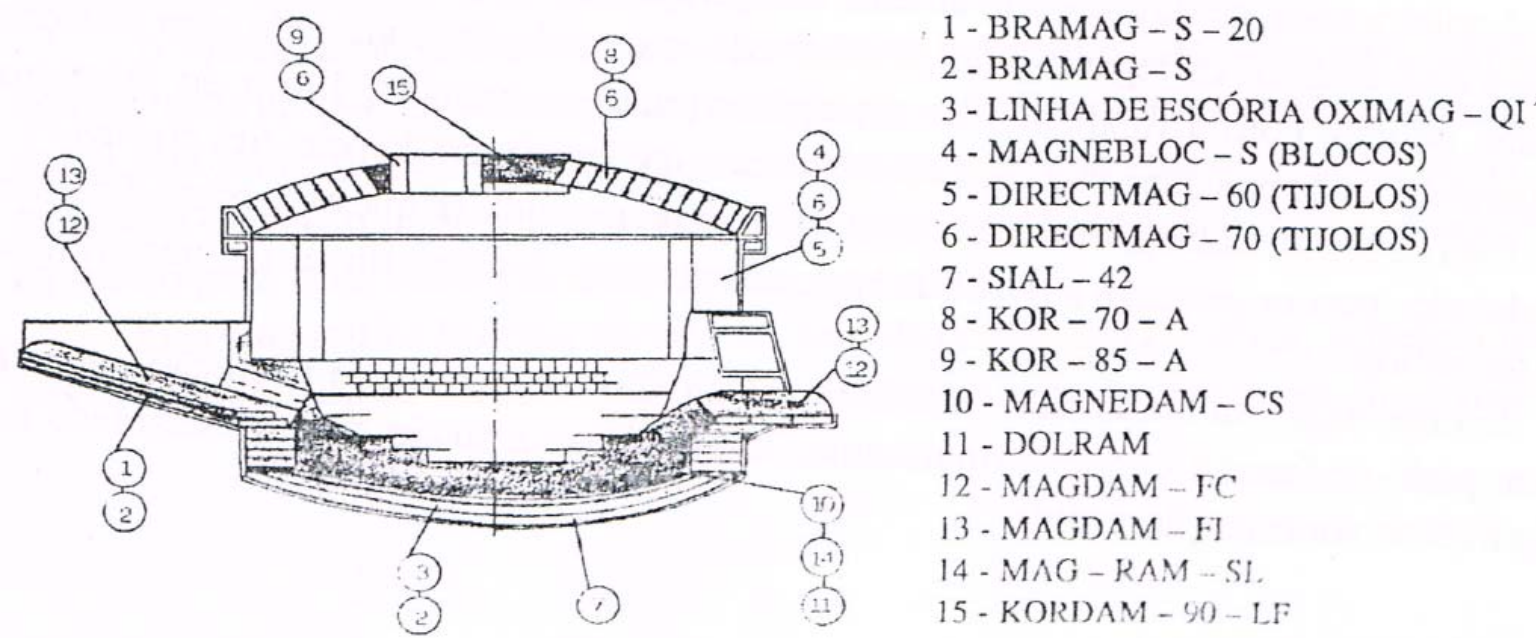

Figura 1. Representação esquemática do revestimento refratário de um FEA, conforme orientações Magnesita S/A [1].

Com o objetivo inicial de reduzir os tempos de paralisação de um FEA para reparos refratários, painéis refrigerados à água passaram a ser utilizados em locais específicos das paredes laterais do FEA, carcaça superior. Os excelentes resultados alcançados induziram à ampliação do uso de painéis refrigerados em toda carcaça superior do FEA, abóbada e miolo da abóbada.

Os painéis refrigerados são instalados a cerca de $350 \mathrm{~mm}$ acima do nível do banho de aço líquido e sua conexão com o sistema de refrigeração é feita pela parte traseira do painel, através de tubos flexíveis e válvulas esféricas.

Os primeiros painéis refrigerados eram feitos de chapa de aço especial com um sistema interno de chicanas para o direcionamento do fluxo de água, Figura 2. Estes painéis refrigerados ficaram conhecidos com painéis "tipo caixa". Atualmente os painéis refrigerados são fabricados com tubos, que podem ser de aço ou cobre. Estes painéis são submetidos a um fluxo forçado de água de refrigeração, com vazão que tipicamente varia de 10 a $15 \mathrm{~m}^{3} / \mathrm{h}$ para cada metro quadrado de painel. Os painéis são projetados para que durante funcionamento normal de operação a água de refrigeração, em todo seu trajeto, sofra uma elevação de temperatura entre 10 e $35^{\circ} \mathrm{C}$, dependendo de sua posição de montagem. A utilização de painéis tubulares possibilitou uma redução no volume de água circulante, quando comparado a seus antecessores, os painéis do "tipo caixa" [1].

* Contribuição técnica ao $45^{\circ}$ Seminário de Aciaria - Internacional, 25 a 28 de maio de 2014, Porto Alegre, RS, Brasil. 

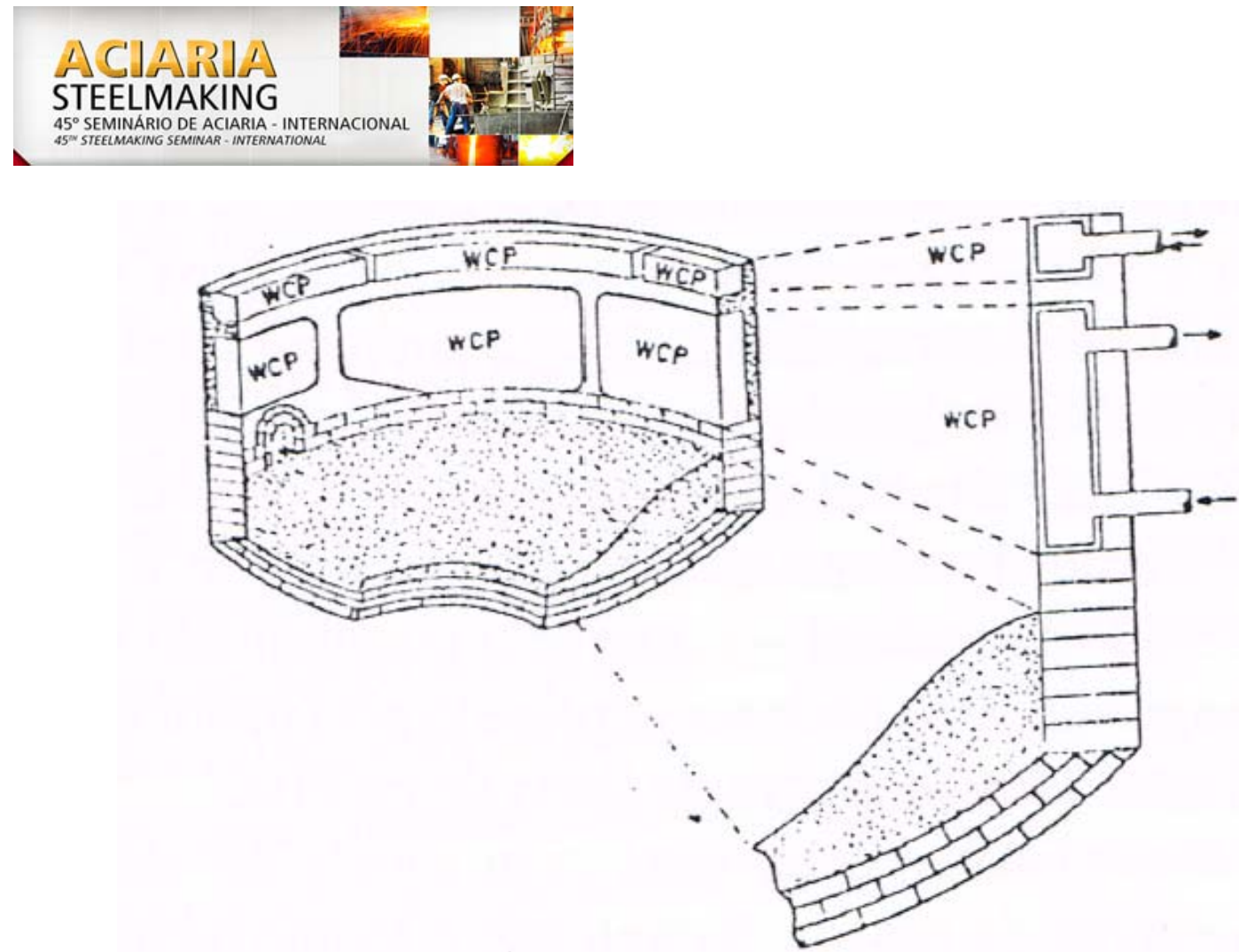

Figura 2. Representação esquemática da instalação dos primeiros painéis refrigerados em FEA. Painéis tipo "Caixa" [1].

Algumas das vantagens obtidas com a utilização de painéis refrigerados nos FEA foram:

a) Aumento de produtividade;

b) Eliminação da necessidade de reduzir a potência durante o período de banho plano;

c) Redução do tempo de reparo com material refratário;

d) Redução do tempo para montagem de um novo forno (revestimento refratário), pois reduz a área para refratamento;

e) Redução do consumo de refratários, sendo uma importante vantagem econômica.

Apesar das grandes vantagens introduzidas pelo uso dos painéis refrigerados nos FEA, pelo menos dois fatores inerentes ao uso de painéis refrigerados nos FEA preocupavam seus usuários. O primeiro fator diz respeito ao aumento de perdas térmicas no processo de fabricação do aço em função da extração de calor feita pela água de refrigeração dos painéis, porém estudos posteriores refutaram este argumento e comprovaram que o aumento das perdas térmicas com a utilização dos painéis refrigerados nos FEA é altamente compensado pela maior utilização do forno e pela economia no uso de material refratário.

O segundo fator remete aos riscos de vazamentos da água de refrigeração dos painéis para o interior do FEA. O fluxo de água de refrigeração dos painéis é contínuo, porém o aporte térmico que incide sobre os painéis varia ao longo do processo de fabricação do aço (corrida), fazendo com que os painéis sofram com a fadiga termomecânica de seus tubos, decorrentes das diversas dilatações e contrações dos mesmos.

A fadiga térmica dos tubos provoca o surgimento de micro trincas, que se propagam e ocasionam pequenos vazamentos de água para o interior do FEA. Com o passar do tempo essas micro trincas podem evoluir, elevando a quantidade de água vazada para o interior do FEA. Outros fatores também podem provocar o vazamento de água para o interior do FEA, como: furos em painéis devido ao rebote de chama e/ou splash de oxigênio, rompimento de mangueiras, etc.

* Contribuição técnica ao $45^{\circ}$ Seminário de Aciaria - Internacional, 25 a 28 de maio de 2014, Porto Alegre, RS, Brasil. 
Mesmo os pequenos vazamentos de água no interior do FEA podem provocar acidentes de alto risco nas aciarias. Estes pequenos vazamentos, tipicamente são muito difíceis de serem detectados pelos operadores e até mesmo por sistema de detecção, porém podem provocar a hidratação do revestimento refratário, levando água para a interface refratário x carcaça, podendo gerar explosões e/ou furos nos fornos [2].

Os grandes vazamentos de água, quando ocorridos nos momentos de preparação (set up) do FEA, são mais fáceis de serem observados pelos operadores, porém quando ocorridos ao longo da corrida, o que é mais comum, rapidamente conseguem alagar o interior do FEA. De acordo com Chevrand [2], talvez o único sinal emitido por este tipo de vazamento que pode ser observado visivelmente durante o processo de fabricação do aço seja a presença de uma chama azulada entre os eletrodos e também pela exaustão do despoeiramento. Grandes vazamentos de água no FEA, em geral, são responsáveis por grandes explosões e projeções e material incandescente para fora do FEA. Isto ocorre quando o excesso de água presente no interior do FEA é "recoberta" por material líquido incandescente (seja o aço líquido e/ou escória) deflagrando a ocorrência de dois fenômenos químicos: o primeiro é o aumento da velocidade de ebulição da água formando vapor e, em paralelo, ocorre também a dissociação do hidrogênio da água. Estes fenômenos provocam uma expansão volumétrica que rapidamente é pressurizada no interior desta "cobertura" de aço e/ou escória. O rompimento desta camada de aço e/ou escória significa uma explosão sem qualquer aviso prévio, em função da velocidade das reações.

Normalmente a detecção de vazamentos de água nos FEAs é baseada na inspeção visual do FEA, fato este totalmente dependente da expertise dos operadores do FEA. Existem também sistemas automatizados para detecção de vazamentos de água em painéis refrigerados. Tipicamente estes sistemas de detecção baseiam-se na medição de vazão e pressão da água e/ou na análise dos gases de exaustão do FEA. Estes sistemas, de forma geral, pecam por apenas detectarem grandes vazamentos de água, pelo baixo tempo de resposta do sistema e por não indicarem exatamente a localização dos vazamentos de água.

A Tecnologia ELD, desenvolvida pela Lumar Metals, apresenta uma proposta inovadora no monitoramento e detecção de vazamentos de água em painéis refrigerados do FEA. Através da análise e combinação de dados coletados individualmente em cada painel refrigerado a Tecnologia ELD mostrou-se capaz de detectar, pontualmente, vazamentos de 0,2 I/min em até 10 segundos após sua ocorrência.

\section{OBJETIVOS}

O presente trabalho tem como objetivo apresentar como a Tecnologia ELD pode ser implantada em um FEA e como pode ser realizada a integração desta tecnologia com os sistemas de automação existentes. Também será apresentado o atual estágio de desenvolvimento da Tecnologia ELD, suas etapas de testes e os resultados obtidos ao longo do processo de desenvolvimento.

\section{MÉTODO}

Em geral os menores vazamentos detectáveis pelos atuais sistemas de detecção de vazamentos de água em FEA estão na ordem de 30 a 40 l/min (dependendo da

* Contribuição técnica ao $45^{\circ}$ Seminário de Aciaria - Internacional, 25 a 28 de maio de 2014, 
pressão de operação do sistema de refrigeração, este vazamento pode ser equivalente a um furo no tubo do painel de 5,0 a 9,0 mm de diâmetro). Outra característica destes atuais sistemas é o tempo de resposta para confirmação do vazamento de água. Em determinados casos, a confirmação do vazamento pode demorar o tempo equivalente a duas corridas do FEA.

Sem dúvidas as características citadas acimas contribuem para a detecção de vazamentos e prevenção de acidentes em aciarias, porém os pequenos vazamentos de água que não são detectáveis por estes sistemas continuam possuindo grande potencial de acidente durante a operação de FEA e até mesmo os grandes vazamentos, que são detectáveis pelos sistemas, deixam os operadores em risco durante o longo período de confirmação do vazamento.

Com o objetivo de reduzir consideravelmente os riscos de exposição dos operadores e equipamentos aos riscos e intempéries provocados pela presença de água no interior do FEA a Lumar Metals investiu no desenvolvimento da Tecnologia ELD, adotando como premissas principais: o desenvolvimento de um sistema capaz de monitorar os painéis refrigerados de forma contínua ( 24 horas por dia) e detectar vazamentos de água com vazões inferiores a $10 \mathrm{l} / \mathrm{min}$ com tempo de resposta inferior a 2,0 minutos.

Incialmente estudos técnicos e teóricos foram realizados para a identificação dos parâmetros mais relevantes para a detecção dos vazamentos de água em painéis refrigerados e quais as técnicas seriam utilizadas para coletar todas as informações necessárias para identificação do vazamento. Posteriormente, testes de funcionamento foram realizados em laboratório na Lumar Metals.

A etapa de testes "a frio" consistiu na simulação do funcionamento de painéis refrigerados onde vazamentos de água foram provocados nos mesmos. Para tanto, três painéis refrigerados foram montados em um dispositivo específico e conectados a um sistema de refrigeração, Figura 3. Cada painel foi alimentado com aproximadamente $24 \mathrm{~m}^{3} / \mathrm{h}$ de água por circuito. A pressão de água do sistema de refrigeração utilizado durante os testes foi de $6,0 \mathrm{kgf} / \mathrm{cm}^{2}$. O dispositivo coletor de dados da Tecnologia ELD foi posicionado na conexão de saída dos painéis.

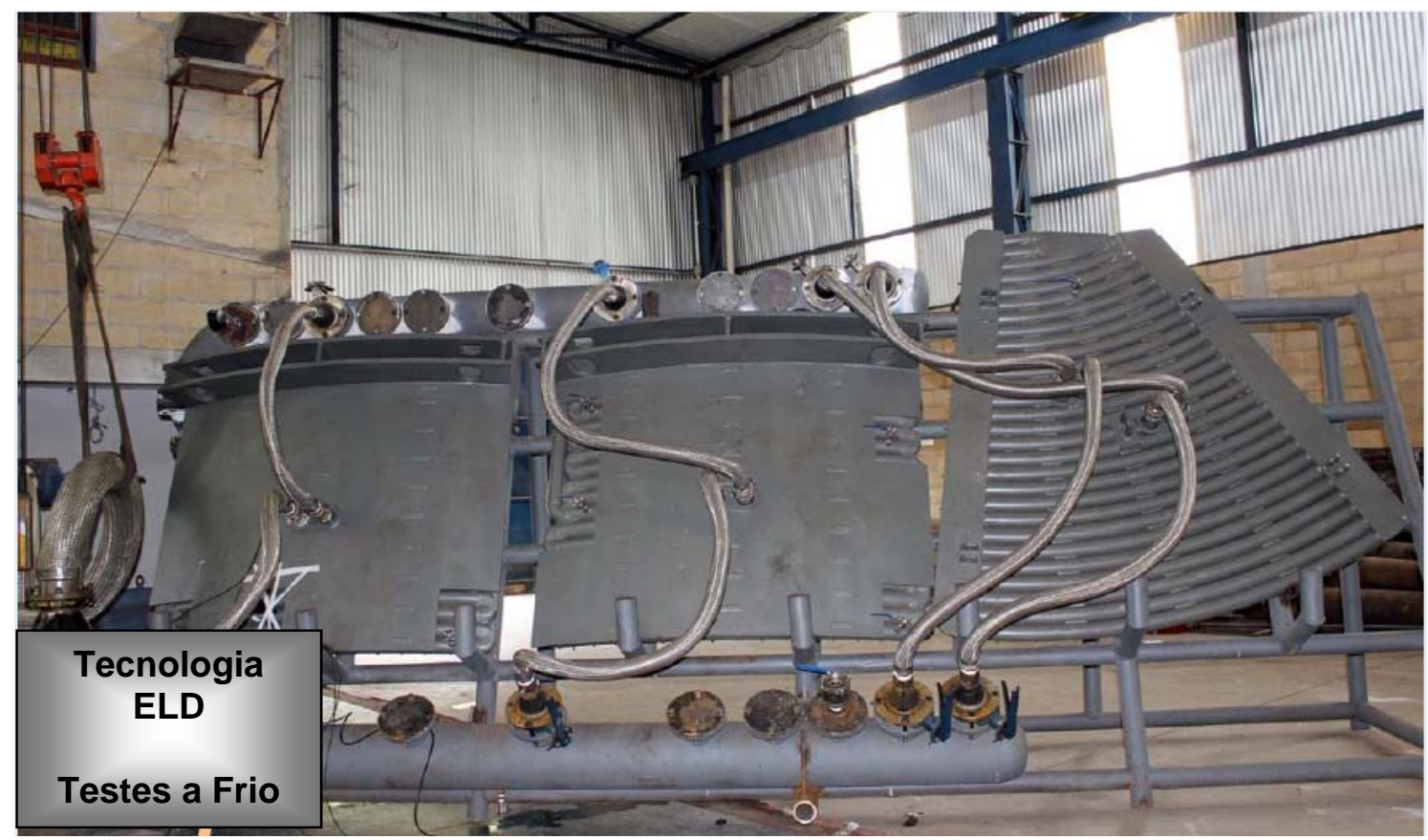

Figura 3. Dispositivo montado para realização dos testes "a frio" da Tecnologia ELD.

* Contribuição técnica ao $45^{\circ}$ Seminário de Aciaria - Internacional, 25 a 28 de maio de 2014, Porto Alegre, RS, Brasil. 
Os vazamentos de água nos painéis refrigerados foram simulados de forma "forçada", utilizando duas metodologias diferentes. Primeiramente foram feitos orifícios em locais aleatórios ao longo do circuito de água dos painéis refrigerados e então válvulas esféricas (DN 1/2") foram instaladas em cada orifício aberto do painel para que quando houvesse a circulação de água no painel não ocorressem vazamentos. Com o sistema de refrigeração em funcionamento (circulação de água) vazamentos em diversos pontos dos painéis refrigerados foram simulados através da abertura das válvulas esféricas instaladas nos painéis refrigerados. Os vazamentos de água foram simulados em diversas intensidades (vazões), desde um pequeno vazamento que provocou apenas uma névoa de água até grandes vazamentos com a válvula totalmente aberta.

A outra forma de vazamento simulado foi através do desbaste do tubo do painel através de ferramenta rotativa. O tubo foi desbastado até que restasse apenas uma fina parede de metal, então uma ferramenta pontiaguda foi utilizada para provocar um pequeno furo no painel. O diâmetro do furo provocado no painel através de ferramenta foi inferior a $1,0 \mathrm{~mm}$.

Durante a etapa de testes "a frio" foi possível analisar a resposta da tecnologia aos vazamentos simulados, repetibilidade e a confiabilidade dos sinais coletados. Porém, esta etapa não permitiu que a tecnologia fosse testada em relação às intempéries de processo do FEA, tais como, exposição ao calor, elevados ruídos sonoros e eletromagnéticos, exposição à poeira e particulados em suspensão e demais condições do ambiente operacional do FEA. Portanto foi definida a realização de uma segunda etapa de testes práticos, desta vez com a Tecnologia ELD instalada em um FEA e os testes realizados durante operação normal do FEA, chamada de testes "a quente".

Os testes "a quente" foram realizados em FEA com capacidade de 100 toneladas, em empresa parceira da Lumar.

$\mathrm{Na}$ etapa de testes "a quente" um dispositivo foi acoplado à conexão de entrada do painel refrigerado para simular a ocorrência de um vazamento de água. O dispositivo consistia em uma derivação do fluxo principal de água do painel onde foram montadas uma válvula do tipo agulha e uma válvula solenoide, conforme está descrito na Figura 4. A válvula do tipo agulha foi utilizada para regular o fluxo de água desejado para o vazamento de água simulado, já a válvula solenoide (normalmente fechada) foi utilizada para provocar de forma remota o vazamento forçado de água. Uma vez que a válvula do tipo agulha estava regulada como fluxo de vazamento desejado, sempre que a válvula solenoide era acionada eletricamente ela passava para sua condição de "aberta" e permitia a passagem do fluxo regulado pela válvula agulha, simulando um vazamento de água no painel. Ao ser retirado o sinal elétrico da válvula solenoide ela retornava a sua condição de "fechada" e estancava o fluxo de água pelo dispositivo, eliminando o vazamento simulado no painel refrigerado. Desta forma os testes puderam ser conduzidos de forma remota, sem a necessidade da presença de um operador ao redor do FEA durante o processo de realização dos testes.

* Contribuição técnica ao $45^{\circ}$ Seminário de Aciaria - Internacional, 25 a 28 de maio de 2014, 

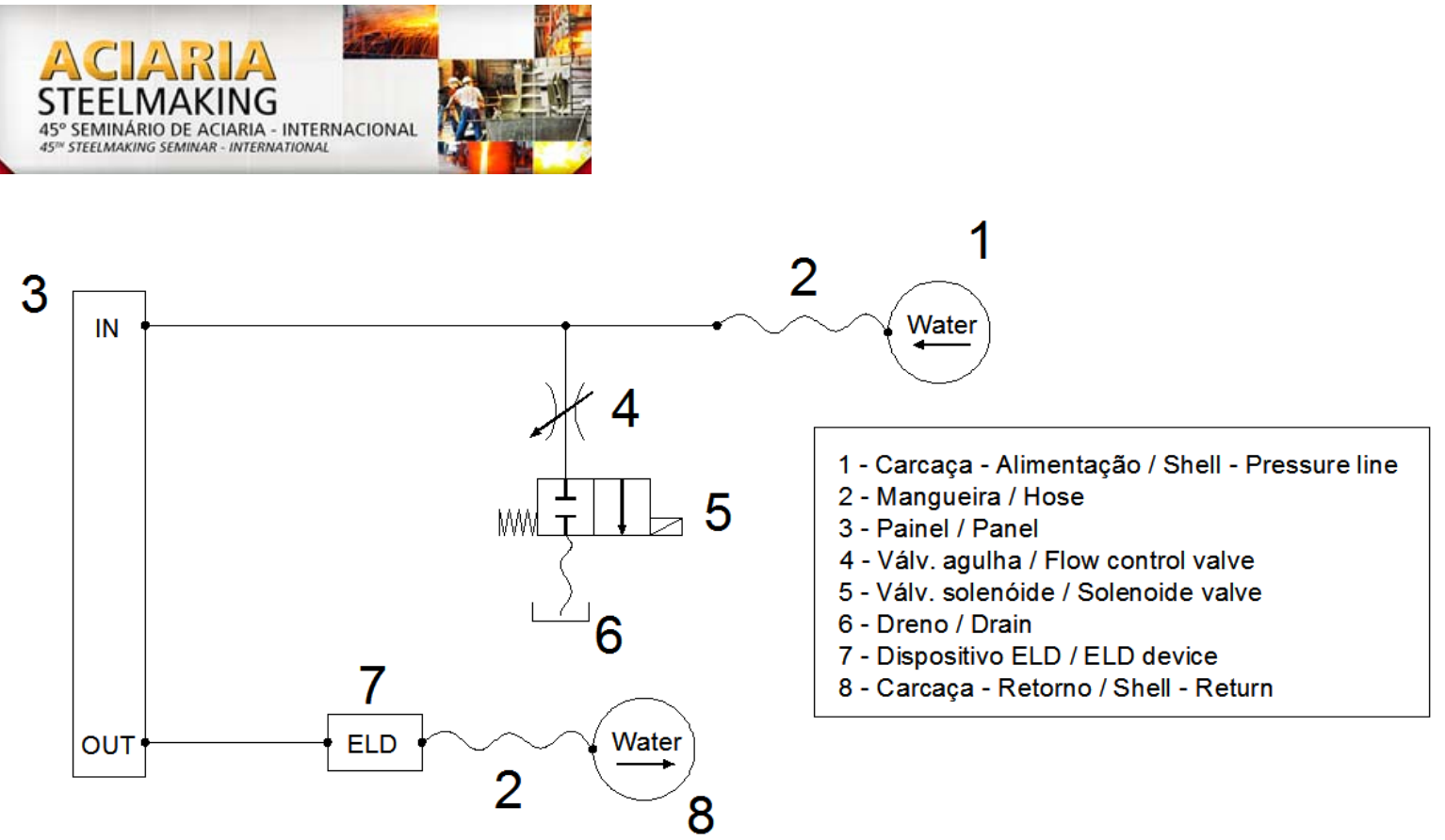

Figura 4. Desenho esquemático do dispositivo para simulação de vazamentos em painéis refrigerados utilizado durante a etapa de testes "a quente" da Tecnologia ELD.

Devido aos riscos da presença de água no FEA, todo volume de água proveniente das simulações de vazamentos dos painéis foi direcionado para um local seguro através do uso de mangueiras hidráulicas. O dispositivo coletor de dados da Tecnologia ELD foi posicionado na conexão de saída dos painéis. A Figura 5 apresenta os dispositivos de testes montados no painel refrigerado do FEA para realização dos testes "a quente" da Tecnologia ELD.

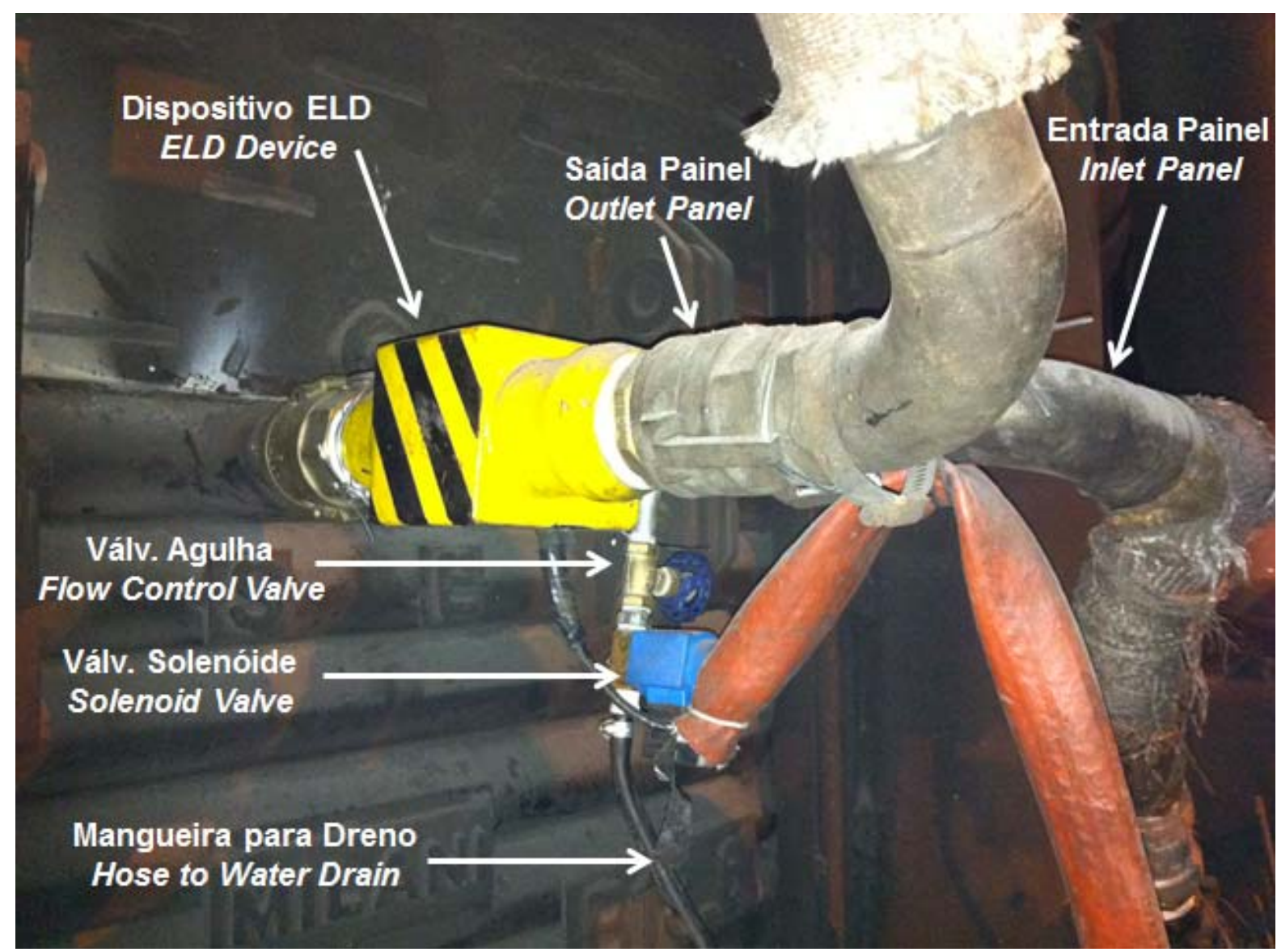

Figura 5. Equipamentos instalados no FEA para realização dos testes "a quente" da Tecnologia ELD.

* Contribuição técnica ao $45^{\circ}$ Seminário de Aciaria - Internacional, 25 a 28 de maio de 2014, Porto Alegre, RS, Brasil. 


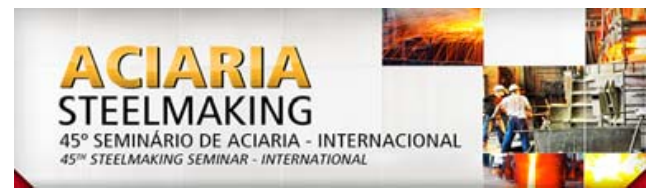

$\mathrm{Na}$ etapa de testes "a quente" mais uma vez foi possível analisar os sinais de resposta da tecnologia aos vazamentos simulados, a repetibilidade e a confiabilidade dos sinais coletados. Os vazamentos foram simulados em uma ampla faixa de vazão de água, a fim de detectar o comportamento do sistema a esta variação de vazão. A tecnologia também foi testada em relação ao ambiente de instalação, não sendo observada nenhuma interferência do ambiente do FEA nas medições feitas pelo sistema.

\section{RESULTADOS E DISCUSSÃO}

Nesta seção serão apresentados os resultados obtidos durante os testes realizados, o atual estado da arte da Tecnologia ELD, o descritivo funcional do sistema proposto e suas principais características.

Os resultados obtidos durante a realização dos testes "a frio" foram totalmente satisfatórios. O sistema acusou a detecção de vazamentos de água com $100 \%$ de exatidão em todas as ocasiões simuladas. O índice de alarmes falsos detectados pelo sistema foi igual a zero.

Ainda na primeira fase de testes do sistema, testes "a frio", foi possível comprovar que, em termos de comportamento dos sinais coletados pelo sistema, existe equivalência entre o sinal captado em função do vazamento de água provocando através de uma válvula esférica instalada no painel e o vazamento de água provocando por um furo real, ao qual o painel foi submetido, Figura 6. Em resumo, para o sistema desenvolvido não importa qual a origem do vazamento de água, seja ele provocado através da abertura de uma válvula e/ou um furo real no painel, o sistema o detecta como "vazamento". Este resultado foi fundamental para continuidade do desenvolvimento da tecnologia, pois em um teste de funcionamento em um FEA não seria possível, pelo menos de forma controlada, provocar vazamentos reais para o interior do FEA.

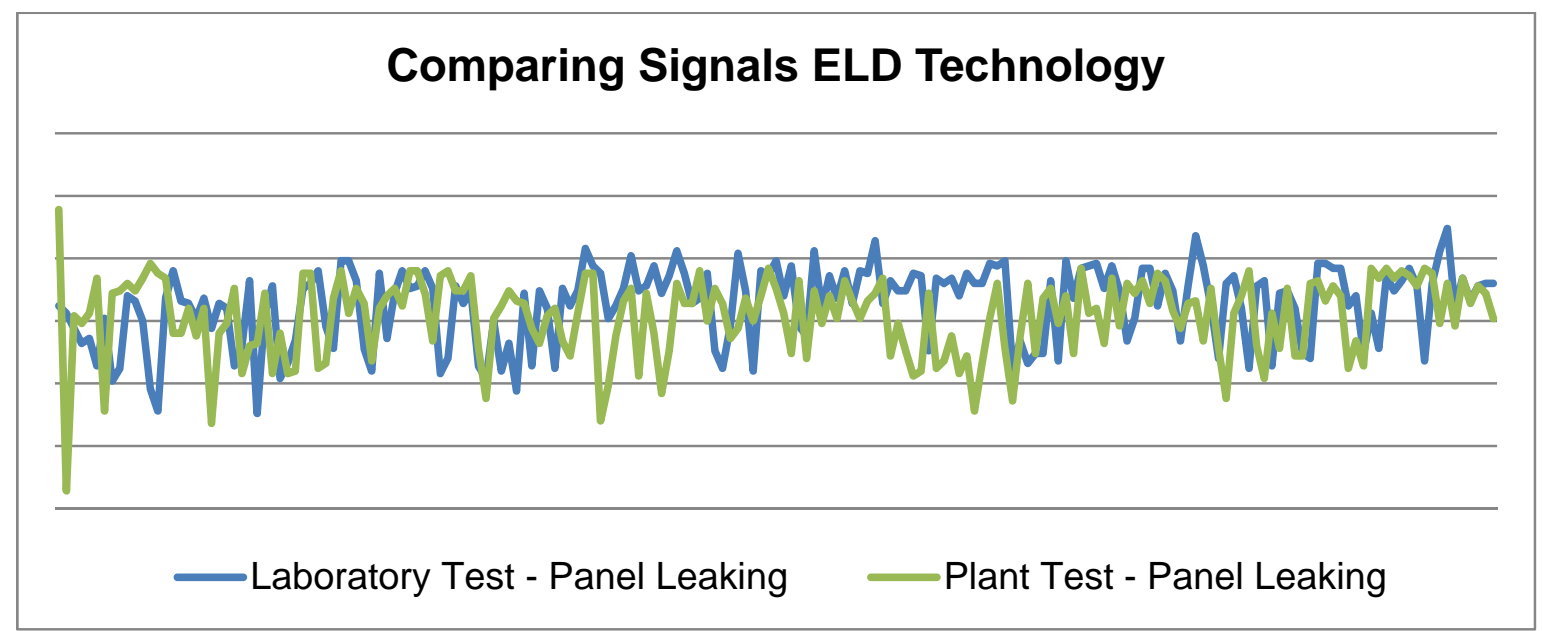

Figura 6. Comparação gráfica dos sinais coletados pelo sistema da Tecnologia ELD durante a ocorrência de um vazamento induzido através de válvula e vazamento real.

Os resultados obtidos na segunda etapa de testes, testes "a quente" foram similares aos resultados obtidos na primeira etapa, ou seja, o sistema foi capaz de detectar $100 \%$ das ocorrências de vazamentos simulados. Nesta etapa os índices de alarmes falsos detectados pelo sistema também foi igual a zero. A Figura 7 apresenta a representação gráfica dos sinais coletados ao longo do tempo. Note que existem

* Contribuição técnica ao 45 Seminário de Aciaria - Internacional, 25 a 28 de maio de 2014, Porto Alegre, RS, Brasil. 


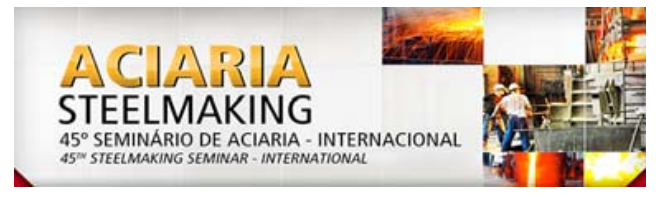

dois patamares de intensidade de sinal, o patamar inferior representa o painel em operação normal, sem vazamentos de água, já o patamar superior indica que há a presença de vazamento de água naquele circuito monitorado.

As etapas de testes realizados também serviram para que fossem enumeradas as melhorias para a tecnologia, tal como a utilização de dispositivos wireless para evitar a necessidade de novos cabeamentos ao redor do FEA.

A Tecnologia ELD é composta pelos principais componentes:

a) Coletores de Dados Wireless: são os dispositivos responsáveis pelo monitoramento contínuo dos circuitos de refrigeração e envio dos dados coletados para a estação de trabalho para que estes sejam processados;

b) Estação Base: é a unidade responsável pela recepção, via wireless, dos dados coletados pelo sistema e envio dos mesmos para a Estação de Trabalho através de protocolo de comunicação serial;

c) Estação de Trabalho: é a unidade responsável pela análise de dados e emissão de alarmes;

d) Supervisório: Tela de supervisório, programada em software scada, onde será apresentado continuamente o status de cada circuito monitorado.

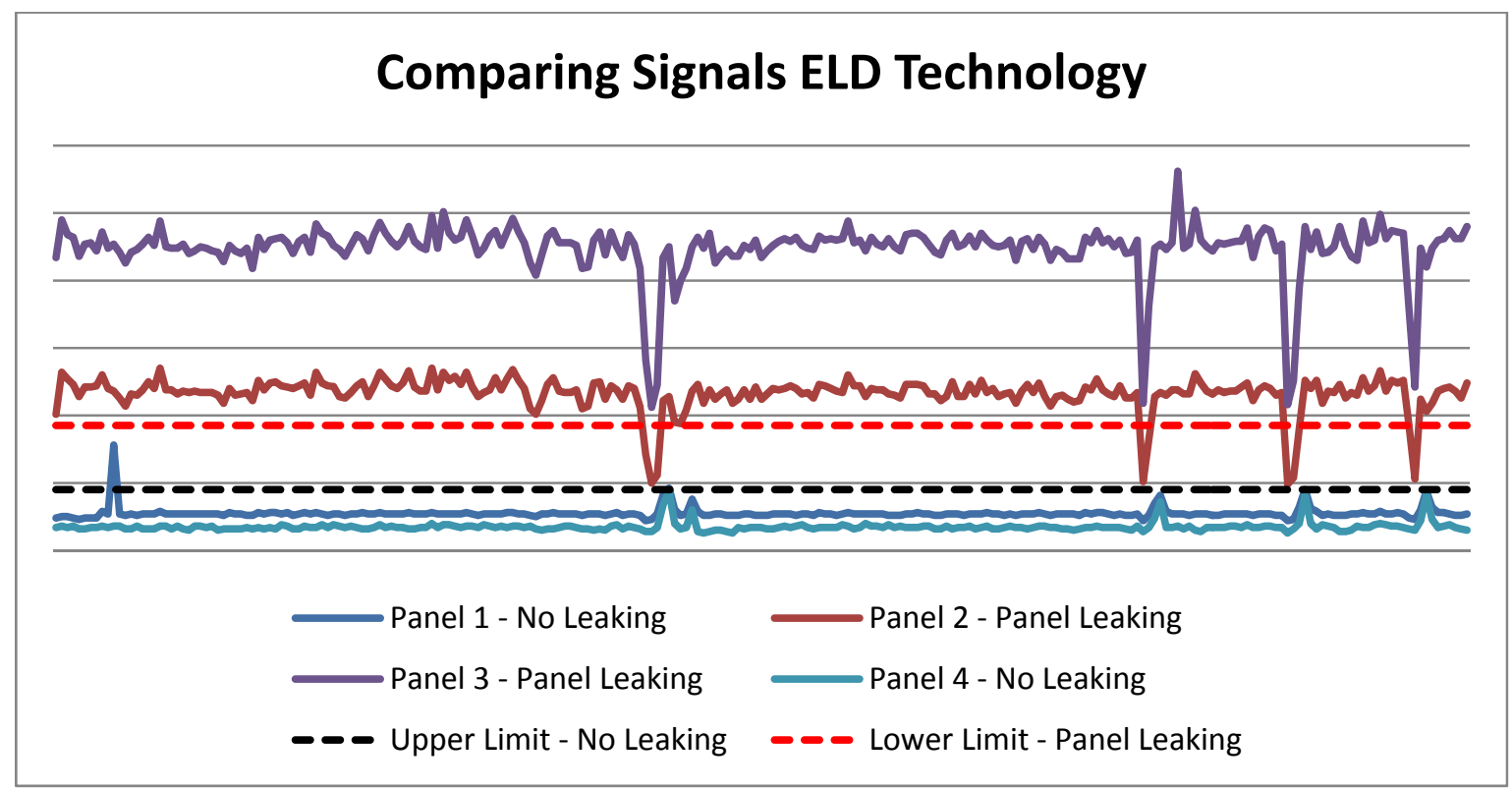

Figura 7. Representação gráfica dos sinais coletados pelo sistema da Tecnologia ELD.

A arquitetura final da Tecnologia ELD está apresentada na Figura 8.

* Contribuição técnica ao 45 Seminário de Aciaria - Internacional, 25 a 28 de maio de 2014, 

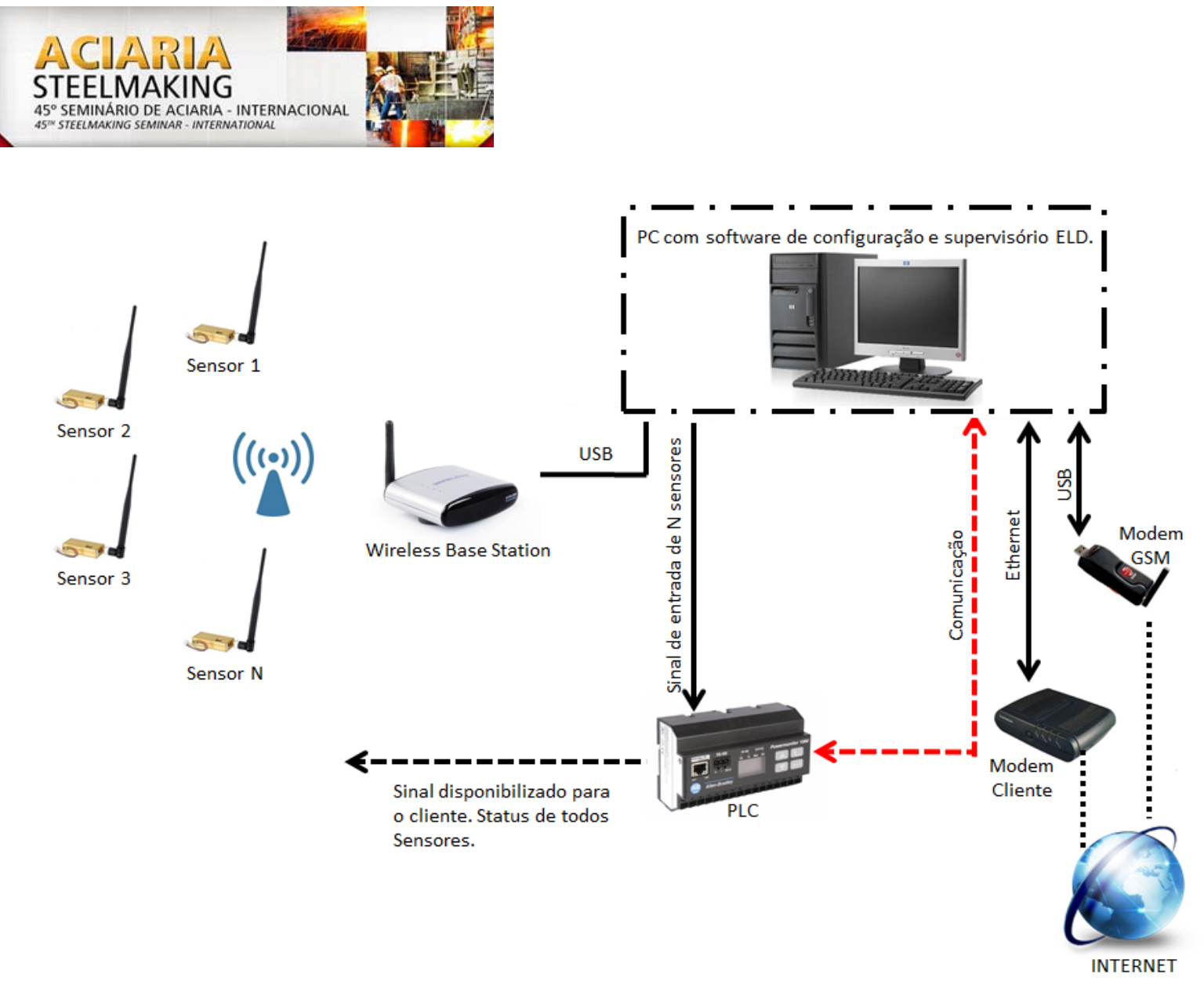

Figura 8. Arquitetura básica de montagem da Tecnologia ELD.

Resumidamente, o funcionamento da Tecnologia ELD dar-se-á da seguinte forma: os coletores de dados monitoram individualmente cada circuito e enviam para Estação Base os dados coletados através de tecnologia wireless. A Estação Base organiza e envia os dados recebidos para a Estação de Trabalho através de protocolo comunicação serial. Na Estação de Trabalho os dados de cada circuito monitorado serão processados através de software específico e o status de cada painel é disponibilizado para programa PLC e Tela de Supervisório Scada. O status de cada circuito monitorado também é disponibilizado para o cliente através de saída digital em PLC do próprio sistema da Tecnologia ELD. A Tecnologia ELD também permite, de forma segura, o acesso remoto de seu sistema para configurações, atualizações e procedimentos de calibração.

\section{CONCLUSÃO}

Os excelentes resultados obtidos em todos os testes credenciaram a Tecnologia ELD para a implantação definitiva de seu sistema de detecção em um FEA. Uma empresa parceira da Lumar Metals fez recentemente a aquisição da tecnologia, que possui previsão de start up em Fevereiro/14.

Apesar de todos os testes realizados da Tecnologia ELD terem sido realizados em painéis refrigerados de FEA a aplicação da Tecnologia ELD não está restrita a estes equipamentos. A Tecnologia ELD também poder ser utilizada em dutos de sistemas de despoeiramento, injetores, blocos, etc.

\footnotetext{
* Contribuição técnica ao $45^{\circ}$ Seminário de Aciaria - Internacional, 25 a 28 de maio de 2014, Porto Alegre, RS, Brasil.
} 
As principais características da Tecnologia ELD são:

- Fácil instalação, pois não requer alterações de projeto dos painéis refrigerados;

- Monitoramento contínuo, 24 horas online de monitoramento e processamento de dados em estação de trabalho dedicada;

- Utilização de protocolo de comunicação wireless, portanto não requer passagem de cabos elétricos ao redor do FEA;

- Fácil integração com sistemas supervisórios já existentes;

- Sistema totalmente automatizado, não requer intervenção de operadores para identificação dos vazamentos de água;

- Identificação precisa de cada circuito e/ou painel que apresente vazamento;

- Baixíssimo tempo de resposta do sistema. Vazamentos detectados em até 10 segundos após sua ocorrência;

- Detecta vazamentos a partir de 0,2 l/min.

\section{REFERÊNCIAS}

1 Silveira RC. Fabricação de aço em fornos elétricos. Ouro Preto: Editora UFOP; 1997.

2 Chevrand LJS. Acidentes em aciaria. In: ABM. Anais do $35^{\circ}$ Seminário de Aciaria Internacional; 2004, Salvador, Brasil. São Paulo: ABM. 2004.

* Contribuição técnica ao 45 Seminário de Aciaria - Internacional, 25 a 28 de maio de 2014, Porto Alegre, RS, Brasil. 